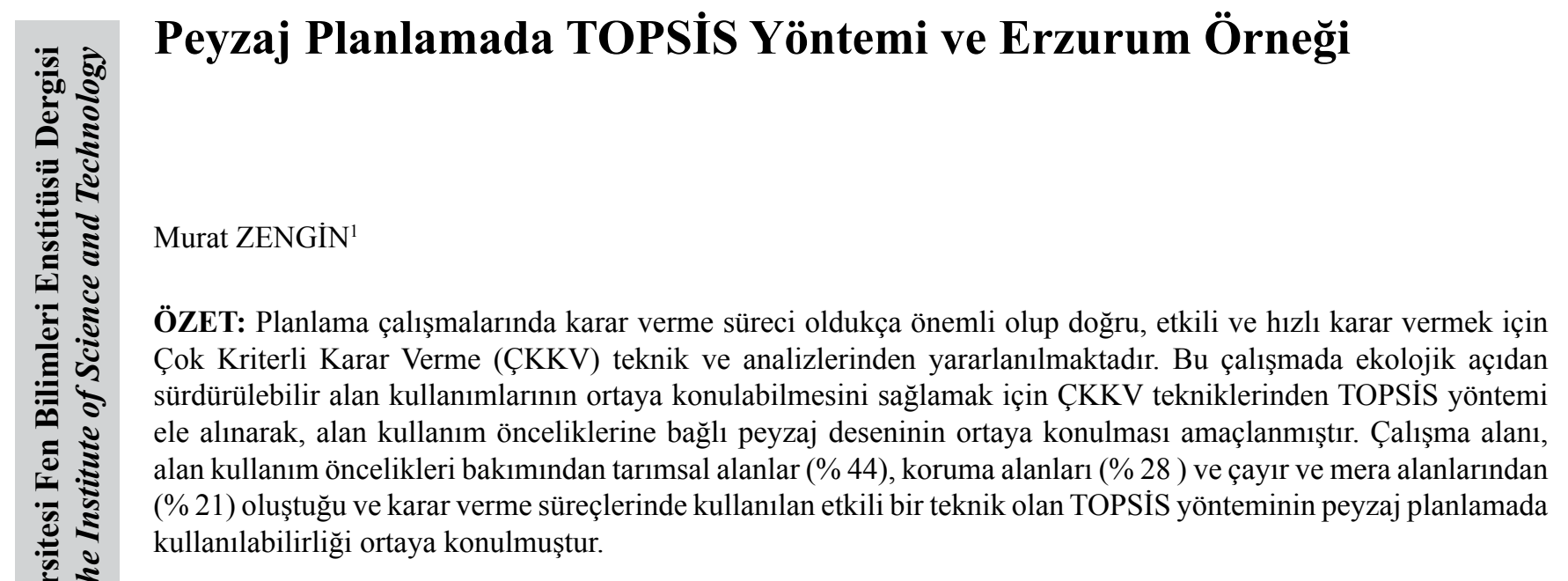

Anahtar Kelimeler: Çok kriterli karar verme (ÇKKV), Erzurum, peyzaj planlama, TOPSíS

\title{
TOPSIS Method in Landscape Planning and Erzurum Example
}

\begin{abstract}
The making decision process is quite important in planning studies and the techniques and analysis of multi criteria decision making (MCDM) have been utilized to make decision accurately, effectively and rapidly. To supply to find out sustainable land uses according to ecological way by handling TOPSIS method which is one of the MCDM techniques, it has been aimed to reveal the landscape pattern in the sense of the first priority of land uses. In this study area, accordıng to land uses priority it has been determined that rural area (44\%), protected area $(28 \%)$ and meadow and pasture $(21 \%)$ have been occured. In this study it has been experienced to find out an effective technique using in making decision process can be used as a method in landscape planning.
\end{abstract}

Keywords: Erzurum, landscape planning, multi criteria decision making (MCDM), TOPSİ

Pamukkale Üniversitesi, Mimarlık ve Tasarım Fakültesi, Peyzaj Mimarlığı, Denizli, Türkiye

Sorumlu yazar/Corresponding Author: Murat ZENGiN, mzengin@pau.edu.tr 


\section{GİRİŞ}

Günümüzde nüfus artışına paralel olarak kentleşme, sanayileşme, toprak, hava ve su kirliliği, orman yangınları, sulak alanların kurutulması, tarımsal amaçlar için yoğun kullanılan gübre ve ilaçlar, doğal kaynakların aşırı kullanımları insan etkileri sonucu hızla artmaktadır. Buna bağlı olarak doğal kaynaklar ihtiyacı karşılamakta zorlanmakta, yetersiz kalmakta ve bozulmaktadır (Kırımhan, 2005). Yanlış alan kullanımları çayır, mera ve orman kaynaklarının tahribine, su kaynaklarının kirlenmesine, erozyona, mikroklimanın değişmesi gibi pek çok sorunun ortaya çıkmasına neden olmaktadır (Karaelmas, 2003). Yanlış arazi kullanımından kaynaklanan bu tip sorunların önlenmesi ve en uygun arazi kullanımının sağlanması, mevcut arazi karakteristikleri ve potansiyellerinin belirlenerek, ekolojik yapıya uygun arazi kullanımlarının uygulanması ile başarılabilir (Malczewskı, 2004). Alan kullanım çalışmalarında genellikle ekolojik süreçler ile sürdürülebilirlik göz önünde bulundurulmamaktadır (Şahin, 1996; Yılmaz, 1998). Altaban (1996)'a göre, ekolojik planlamada amaç, ekolojik, sosyal ve ekonomik verilere eşdeğer önem vererek, alan kullanımları için optimal bir uyum sağlamaktır. Ekolojik temelli araștırmacılar, korumaya ağırlık veren, kaynakların sınırlı olduğu gerçeğini vurgulayan ve ekosistemlerin çok hassas tasıma kapasiteleri olduğunu 1srarla ifade eder.

Ekolojik plan, sektörler arasında dengeli bir kullanımı gerçekleştirmeyi amaçlar ve bunu gerçekleştirirken doğal potansiyelin korunmasına dikkat eder. Alan kullanım etkileşimlerine bağlı olarak, olumsuz etkileri en aza indirmeyi ve doğal kaynakları koruyup geliştirmeyi hedef alır (Altan, 1991). Arazi değerlendirmesinin, arazinin topoğrafya, iklim, bitki örtüsü, toprak ve diğer özelliklerinin yorumlanmasına dayanarak belli arazi birimleri için en uygun kullanımların neler olacağını saptamak ve farklı arazi birimleri arasında kıyaslama yapabilmek amaciyla yapılan çalışmaları içerdiğini belirtmiştir (Özcan, 1991). Arazinin en iyi şekilde değerlendirilmesi amacıyla uygun alan kullanımlarının tespitinde, farklı kriterlere puanlama ve ağırlık değerleri verilmektedir. Ağırlıkların hesaplanmasında ise son zamanlarda artık Çok Kriterli Karar Verme (ÇKKV) yöntemlerinden yararlanılmaktadır. Akpınar (2003)'e göre, "Bu tür yöntemler, planlama çalışmalarında plancının bilgi birikimini ve deneyimini sezgileriyle birleştirerek etkin bir şekilde yorumlamasına, kullanmasına olanak sağlar ve planlamaya 1şık tutar". Peyzaj planlama yöntemleri sinırlıda olsa zaman içinde gelişme göstermesine rağmen, planlamada karar verme süreci oldukça karmaşık olabilmekte, bu sebeple olası hataları en aza indirebilmek için çok kriterli karar verme teknik ve analizlerinden yararlanılmaktadır (Ayhan ve Hepcan, 2009). ÇKKV teknikleri, problemlerin analiz edilmesi, alternatif çözümlerin üretilmesi ve alternatiflerin değerlendirilmesi için ideal kapasiteye sahiptir. TOPSİS yönteminde bütün alternatiflerin pozitif ve negatif ideal çözüme olan uzaklıkları hesaplanır. Yöntemin temeli, seçilen alternatifin pozitif ideal çözüme en yakın mesafede, negatif ideal çözüme ise en uzak mesafede olması oluşturur. Yöntem, pozitif ideal çözüme en yakın olan alternatifi en iyi alternatif olarak kabul eder (Tong et al., 2004; Cheng et al., 2002). TOPSİS yönteminde, ideal çözüm için gerekli olan yakınlık bulunurken hem pozitif ideal çözüme uzaklık hem de negatif ideal çözüme uzaklık dikkate alınır. $\mathrm{Bu}$ uzaklıklar yardımıyla elde edilen yakınlık katsayıları kullanılarak siralama yapılır (Janko and Bernroider, 2005). Bu yöntem çeşitli alternatiflerin, seçilen kriterler açısından analitik bir yöntem ile sıralandığı ve karar vericilere yol gösterici olabilecek niteliktedir. ÇKKV tekniklerinden olan bu yöntem ile yargıya dayalı karar verme sürecinin potansiyel problemlerini elemine ederek, alınan kararların kalitesinin ve rasyonelliğinin artması sağlanabilmektedir (Sezer ve Saatçioğlu, 2008).

Bu çalışmada, ekolojik açıdan sürdürülebilir alan kullanımlarının ortaya konulabilmesini sağlamak için ÇKKV tekniklerinden TOPSís yöntemi ile alan kullanım öncelikleri belirlenerek buna bağlı peyzaj deseninin ortaya konulması amaçlanmıştır. Çalışmada hassas alanlarda gerçekleştirilecek alan kullanım kararlarının alınmasında ekolojik süreçlerin önemi vurgulanarak, karar verme süreçlerinde kullanılan etkili bir tekniğin peyzaj planlamada yöntem olarak kullanılabilirliği ortaya konulmaya çalışılmıștır.

\section{MATERYAL VE YÖNTEM}

Çalışma alanı olan Erzurum ili Türkiye'nin yüzölçümü bakımından en büyük üçüncü ili olup, 
Doğu Anadolu Bölgesinin ise en büyük ili olma özelliği gösterir. Denizden yüksekliği yaklaşık $1900 \mathrm{~m}$. ve 2014 y1lı itibari ile nüfusu 779 448'dir. Soğuk iklim kuşağında olması nedeni ile sanayisi gelişememiş temel geçim kaynağını ise tarım ve hayvancılık oluşturmuştur. Sadece tarihi ve kültürel bakımından değil aynı zamanda doğal açıdan da oldukça zengin olan il, son yıllarda kış turizmi ile ön plana çıkmaya başlamıştır.

TOPSİS yönteminin örneklenmesinde Erzurum Yakutiye ilçesi sınırları içerisinde yer alan önemli doğa alanı olan, kentsel gelişim ile ilişkilendirilen, farklı çevresel baskıların etkisinde olan ve alan kullanım deseni değişimi yaşayan Sulak Alan (Erzurum Bataklığı) ve yakın çevresi çalışma alanı olarak seçilmiştir. Erzurum bataklıkları, Erzurum şehir merkezinin yaklaşık $3 \mathrm{~km}$. kuzeyinde yer alır. Fırat Nehri'nin ana iki kolundan biri olan Karasu üzerinde bulunur. Geçici ve sürekli bataklıklar, mevsimsel sslak çayırlar ve tarım alanlarından oluşur. 1950 ve 1960 'lı yıllarda bölgede yürütülen kurutma çalışmaları sonucunda geniş yer kaplayan göl ve sazlıklar küçülerek şu andaki durumuna gelmiştir (Anonim, 2015). Erzurum bataklığı; Yakutiye ilçesinde tatlı su gölü ve bataklık alanıdır. Turna popülasyonu ile göç mevsimlerinde önemli sayılarda görülen angıt ve ak kanatlı sumru sayesinde önemli kuş alanları statüsü kazanmıştır. Erzurum ovası Önemli Kuş Alanı sınırları Şekil 1'de verilmiştir (Anonim, 2016).

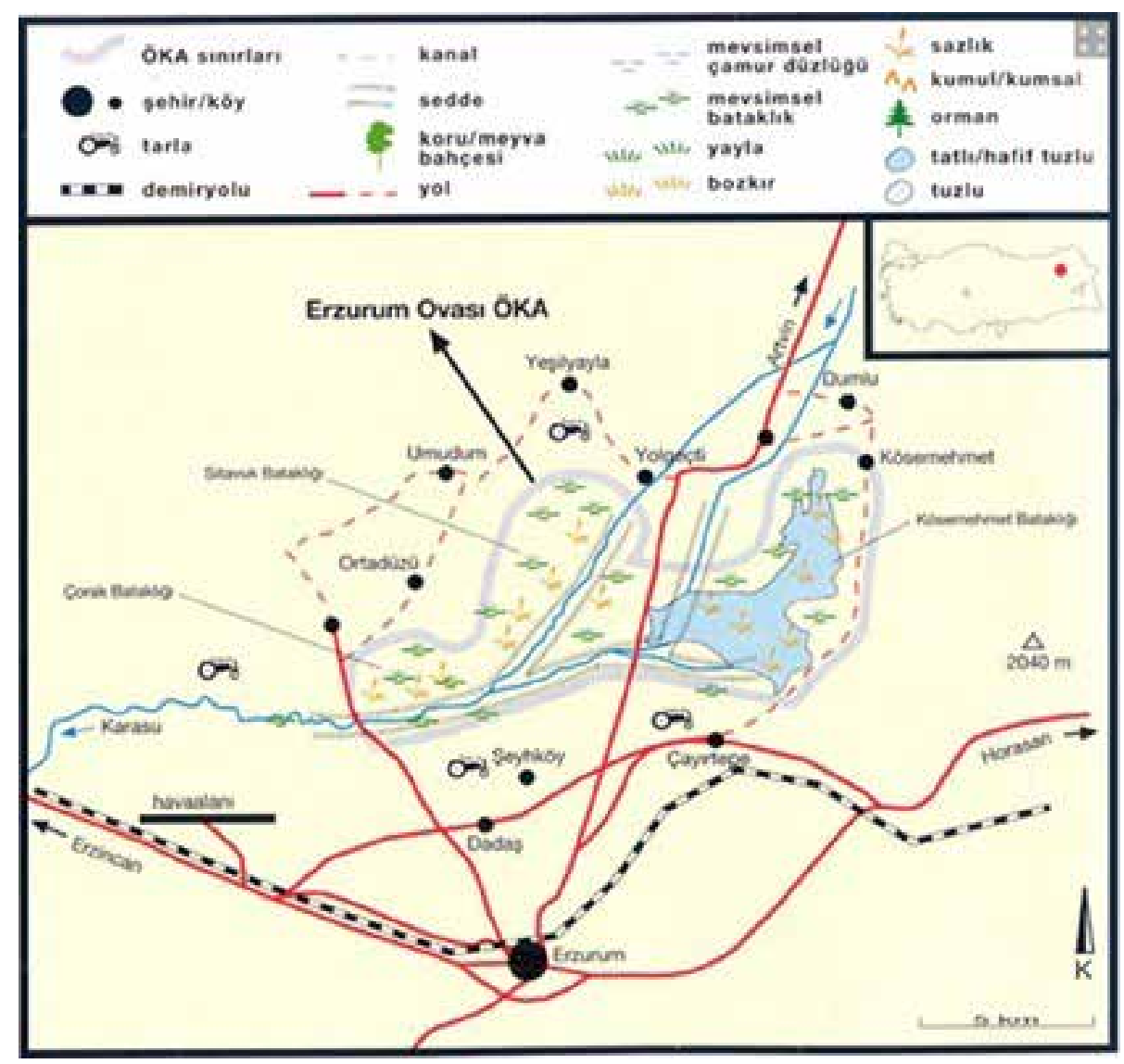

Şekil 1. Erzurum ovası Önemli Kuş Alanı (ÖKA) sınırları haritası (Anonim, 2016)

Erzurum Ovası'nın doğu kenarında yer alan ve daha çok ilkbahar ayları ile yaz başlarında görünür hale gelen Erzurum Bataklıkları Sulak Alanının Koruma Bölgeleri 2006 yılında belirlenmiştir. Ovadaki tehdit ve problemlerin başında bilinçsiz tarımsal faaliyetler, otlatma, havaalanın yer alması, yüksek gerilim hatları, yollar, yapılaşma ve şehirleşme, evsel ve kanalizasyon atıkları, sulak alan kurutma, drenaj kanalları yer almaktadır. Alanda 224 kuş türü tespit edilmiş olup, en önemli kuş türü sürmeli kız kuşudur 
(OSİB, 2015). Sulak alan 1970 yılı başlarında büyük oranda kurutulmuştur. Erzurum ovasında özellikle geçiş mevsimlerinde ortaya çıkan göller sulak alanın doğal yapısının parçalarını olușturmaktadır. Sulak alan Akdeniz-Karadeniz ve Doğu Afrika-Batı Asya kuş göç yollarının kesişim koridoru üzerinde yer aldığg için her iki göç yolunda hareket eden farklı türlerin konakladıkları bir alan durumundadır. $\mathrm{Bu}$ nedenle, Erzurum bataklığında sulak alanların kurutulmasına rağmen, kuşların halen bu alanlarda barınmaya devam ettiği tespit edilmiştir. Erzurum Ovası'nın uluslararası sözleşmelerle koruma altındaki en değerli türü Sürmeli kızkuşudur (Anonim, 2013).

Çalışma alanı ile ilgili olarak, değişik ölçeklerde ve amaçlarda üretilmiş topoğrafik ve kadastral haritalar, jeoloji, toprak ve orman amenajman haritaları ve uydu görüntülerinden materyal olarak yararlanılmıştır. Ayrıca alana ait yazılı ve görsel litearatür ile yönteme ait literatürler, fotoğraf ve slaytlar materyal olarak kullanılmıştır.

Harita verilerinin rektifiye edilmesi, sınıflandırılması, sayısallaştııılması, çakıştırılması, öz nitelik verilerinin oluşturularak analiz ve sorgulamalarının yapılmasında ArcGIS 9,3 yazılım programı ve yöntemin uygulanmasında M.S.Excel yazılımından yararlanılmıştır.

Çalışma alanının konumu, büyüklüğü, topoğrafik yapısı, alan kullanım tipleri ve alanın doğal-kültürel süreçleri ile karakteristik yapısı dikkate alınarak 500 x 500 m.'lik ekolojik hücre boyutunda plankarelere ayrılmıştır. 789 adet plankare 197,25 km²'lik bir alan kaplamaktadır (Şekil 2).
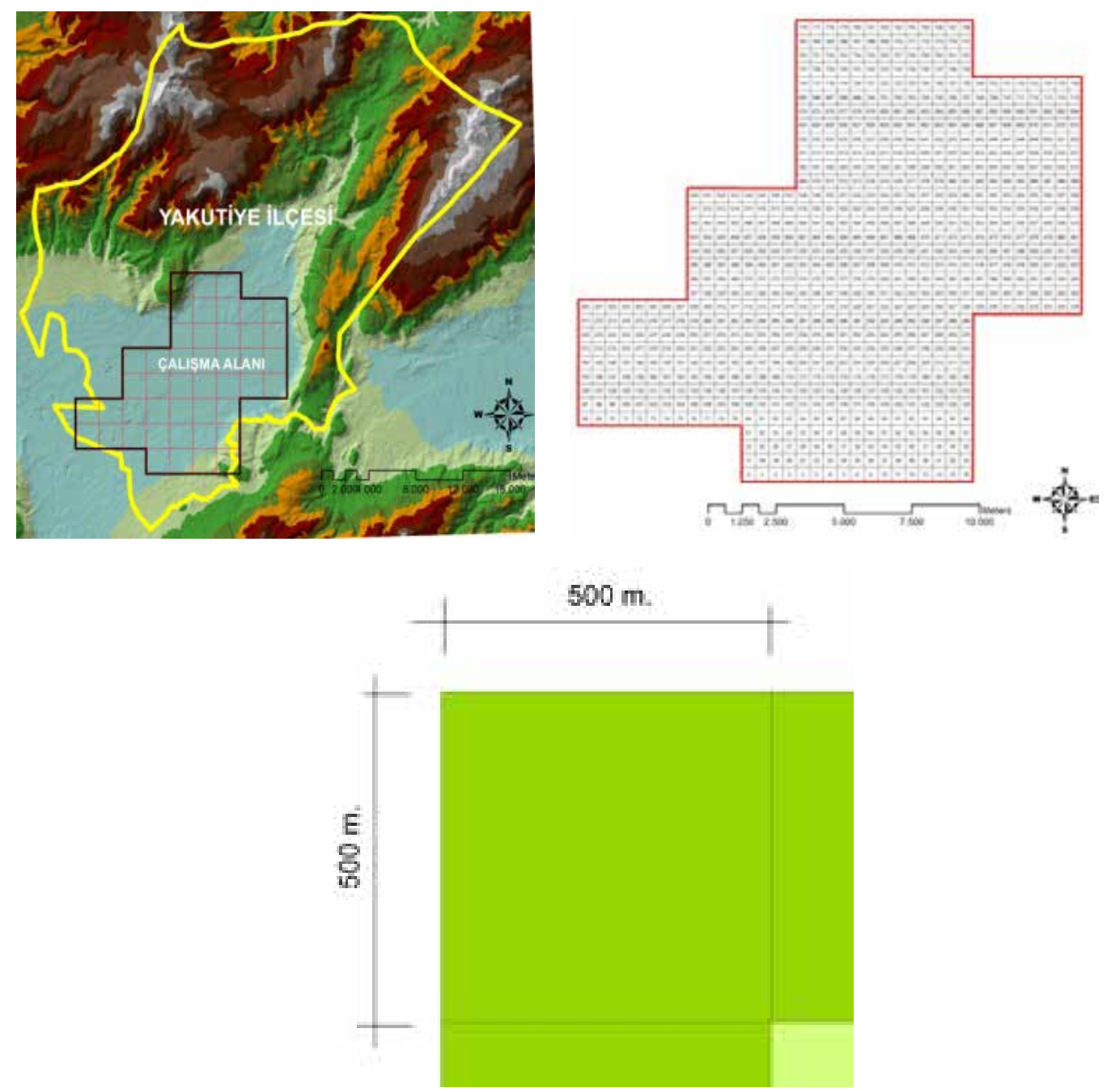

Şekil 2. 500m. x 500m.' lik plankarelere ayrılmış (789 adet) çalışma alanı sınırları 
Çalışma alanında değerlendirme faktörü olarak; (1) arazi kabiliyet yetenek sınıfları, (2) toprak derinliği, (3) mevcut alan kullanımları, (4) büyük toprak grupları, (5) bitki örtüsü, (6) eğim, (7) bak1, (8) yükseklik, (9) jeolojik yap1 ve (10) erozyon durumu ve bunların alt birimleri ele alınmıştır. Alan kullanım önceliği için belirlenen potansiyel alan kullanım tipleri olarak; (1) koruma, (2) tarım, (3) orman, (4) yerleşim, (5) çayırmera alanları seçilmiştir.

Çalışmada her alan kullanım tipi için ayrı ayrı değerlendirme faktörleri ve bu faktörlere bağlı alt birimlere ağırlık puanları (4= çok uygun; $3=$ =ygun, $2=$ az uygun, $1=$ uygun değil) verilmiştir. Her kullanım için uzman değerlendirmelerine bağlı olarak da potansiyel alan kullanım tipleri için uygunluk puanlarının belirlenmesinde etki derecesi (\%) matematiksel yöntemle belirlenmeye çalışılmıştır. Faktörlere alan kullanım tiplerine göre uzmanlar tarafindan verilen göreceli önem puanları ise Çizelge 1'de verilmiştir. Etki dereceleri en önemliden en önemsize doğru puanlama yapılarak 3 gurup üzerinden değerlendirilmiştir (3= Çok Etkili, 2= Etkili, 1= Etkisiz). Çalışmada bir ziraat mühendisi, bir orman mühendisi ve bir peyzaj mimarı olmak üzere üç uzman görüşünden yararlanılmıştır. Uzman Değerlendirmesi; 1-10 arasındaki değerleri önem sirasina göre $(1=$ Önemli; $\ldots \ldots \ldots \ldots \ldots \ldots . . . .$. ..;10=Önemsiz) değerlendirilmiştir, aynı etkiye sahip alt birimlere aynı puanlar verilebilmiştir. Etki derecelerinin bulunmasında Akpınar (1994)'ın geliştirdiği ve Karaelmas (2003)'inda kullandığ 1 ;

$$
\mathrm{DT}=\sum \mathrm{Dfu} \quad \mathrm{Af}=\mathrm{DT} / \sum \mathrm{DT} \text { eşitliklerinden yararlanılmıştır. }
$$

\author{
Eşitlikteki; \\ DT= Uzmanlar tarafinda f değerlendirme faktörüne verilen değerler toplamı \\ $\mathrm{u}=1$ 'den n'e kadar uzman sayis 1 \\ $\mathrm{f}=1$ 'den m'e kadar faktör sayıs 1 \\ $\mathrm{Dfu}=\mathrm{f}$ değerlendirme faktörüne $\mathrm{u}$ uzmanı tarafindan verilen değerler \\ Af $=\mathrm{f}$ değerlendirme faktörünün ağırlığını belirlemektedir.
}

Af'nin aldığı minimum değer ile maksimum değer arasındaki fark bulunup 3'e bölünerek elde edilen değerin minumum değerlere eklenmesiyle guruplama yapılarak 3 gurup (3- Çok Etkili, 2- Etkili ve 1- Etkisiz) oluşturulmuştur. Şeçilen ekolojik faktörlerin hangi potansiyel alan kullanımını ne derece etkilediğini oransal olarak bulabilmek için;

\footnotetext{
$\%$ Etki Derecesi $=\underline{\text { ED X } 100}$ formülü ile değerlendirilmiştir. $\Sigma \mathrm{ED}$
} 
Çizelge 1. Faktörlerin alan kullanım tiplerine göre uzmanlar tarafından verilen göreceli önem puanları

\begin{tabular}{|c|c|c|c|c|c|c|c|c|}
\hline & Değerlendirme Faktörleri / Uzman & 1 & 2 & 3 & DT & Af & Etki Derecesi & $\begin{array}{c}\text { Etki Derecesi } \\
(\%)\end{array}$ \\
\hline \multirow{10}{*}{ 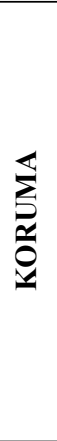 } & Arazi Kabiliyet Yetenek Sınıfları & 4 & 1 & 3 & 8 & 0,06452 & 3 & 15 \\
\hline & Toprak Derinliği & 1 & 2 & 2 & 5 & 0,04032 & 3 & 15 \\
\hline & Mevcut Alan Kullanımları & 6 & 3 & 7 & 16 & 0,12903 & 1 & 5 \\
\hline & Büyük Toprak Grupları & 5 & 7 & 6 & 18 & 0,14516 & 1 & 5 \\
\hline & Bitki Örtüsü & 2 & 3 & 1 & 6 & 0,04839 & 3 & 15 \\
\hline & Eğim & 3 & 1 & 4 & 8 & 0,06452 & 3 & 15 \\
\hline & Bak1 & 7 & 6 & 8 & 21 & 0,16935 & 1 & 5 \\
\hline & Yükseklik Grupları & 8 & 5 & 5 & 18 & 0,14516 & 1 & 5 \\
\hline & Jeolojik Yap1 & 4 & 4 & 9 & 17 & 0,13710 & 1 & 5 \\
\hline & Erozyon & 5 & 1 & 1 & 7 & 0,05645 & 3 & 15 \\
\hline \multirow{10}{*}{$\underset{\underline{z}}{\sum}$} & Arazi Kabiliyet Yetenek Sınıfları & 1 & 1 & 1 & 3 & 0,02679 & 3 & 15 \\
\hline & Toprak Derinliği & 1 & 2 & 2 & 5 & 0,04464 & 3 & 15 \\
\hline & Mevcut Alan Kullanımları & 5 & 6 & 6 & 17 & 0,15179 & 1 & 5 \\
\hline & Büyük Toprak Grupları & 4 & 4 & 3 & 11 & 0,09821 & 2 & 10 \\
\hline & Bitki Örtüsü & 6 & 5 & 5 & 16 & 0,14286 & 1 & 5 \\
\hline & Ĕgim & 2 & 2 & 2 & 6 & 0,05357 & 3 & 15 \\
\hline & Bak1 & 7 & 7 & 6 & 20 & 0,17857 & 1 & 5 \\
\hline & Yükseklik Grupları & 3 & 3 & 4 & 10 & 0,08929 & 2 & 10 \\
\hline & Jeolojik Yap1 & 5 & 4 & 8 & 17 & 0,15179 & 1 & 5 \\
\hline & Erozyon & 2 & 3 & 2 & 7 & 0,06250 & 3 & 15 \\
\hline \multirow{10}{*}{$\sum_{\substack{\underline{j} \\
0}}^{Z}$} & Arazi Kabiliyet Yetenek Sınıfları & 3 & 5 & 3 & 11 & 0,07801 & 2 & 11 \\
\hline & Toprak Derinliği & 2 & 1 & 2 & 5 & 0,03546 & 3 & 16 \\
\hline & Mevcut Alan Kullanımları & 8 & 6 & 4 & 18 & 0,12766 & 1 & 6 \\
\hline & Büyük Toprak Grupları & 7 & 8 & 5 & 20 & 0,14184 & 1 & 6 \\
\hline & Bitki Örtüsü & 1 & 2 & 1 & 4 & 0,02837 & 3 & 16 \\
\hline & Ĕgim & 4 & 7 & 5 & 16 & 0,11348 & 2 & 11 \\
\hline & Bak1 & 5 & 3 & 4 & 12 & 0,08511 & 2 & 11 \\
\hline & Yükseklik Grupları & 6 & 3 & 4 & 13 & 0,09220 & 2 & 11 \\
\hline & Jeolojik Yapı & 9 & 4 & 6 & 19 & 0,13475 & 1 & 6 \\
\hline & Erozyon & 9 & 7 & 7 & 23 & 0,16312 & 1 & 6 \\
\hline \multirow{10}{*}{ 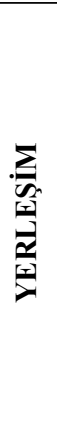 } & Arazi Kabiliyet Yetenek Sınıfları & 3 & 5 & 6 & 14 & 0,08974 & 2 & 10 \\
\hline & Toprak Derinliği & 4 & 6 & 6 & 16 & 0,10256 & 2 & 10 \\
\hline & Mevcut Alan Kullanımları & 5 & 4 & 7 & 16 & 0,10256 & 2 & 10 \\
\hline & Büyük Toprak Grupları & 6 & 9 & 8 & 23 & 0,14744 & 1 & 5 \\
\hline & Bitki Örtüsü & 3 & 3 & 5 & 11 & 0,07051 & 3 & 15 \\
\hline & Eğim & 2 & 2 & 2 & 6 & 0,03846 & 3 & 15 \\
\hline & Bak1 & 8 & 7 & 4 & 19 & 0,12179 & 2 & 10 \\
\hline & Yükseklik Grupları & 9 & 8 & 3 & 20 & 0,12821 & 1 & 5 \\
\hline & Jeolojik Yap1 & 1 & 1 & 1 & 3 & 0,01923 & 3 & 15 \\
\hline & Erozyon & 10 & 10 & 8 & 28 & 0,17949 & 1 & 5 \\
\hline \multirow{10}{*}{ 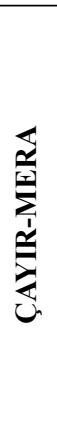 } & Arazi Kabiliyet Yetenek Sınıfları & 1 & 5 & 3 & 9 & 0,05806 & 3 & 14 \\
\hline & Toprak Derinliği & 2 & 1 & 4 & 7 & 0,04516 & 3 & 14 \\
\hline & Mevcut Alan Kullanımları & 5 & 4 & 7 & 16 & 0,10323 & 2 & 9 \\
\hline & Büyük Toprak Grupları & 3 & 6 & 9 & 18 & 0,11613 & 2 & 9 \\
\hline & Bitki Örtüsü & 6 & 2 & 5 & 13 & 0,08387 & 3 & 14 \\
\hline & Eğim & 4 & 3 & 1 & 8 & 0,05161 & 3 & 14 \\
\hline & Bak1 & 7 & 6 & 6 & 19 & 0,12258 & 2 & 9 \\
\hline & Yükseklik Grupları & 8 & 5 & 2 & 15 & 0,09677 & 2 & 9 \\
\hline & Jeolojik Yap1 & 9 & 7 & 8 & 24 & 0,15484 & 1 & 4 \\
\hline & Erozyon & 10 & 7 & 9 & 26 & 0,16774 & 1 & 4 \\
\hline
\end{tabular}


Her bir kullanım için belirlenen etki dereceleri kullanılarak TOPSíS Yöntemi aşamaları sırasıyla uygulanmış, yöntem her bir ekolojik hücrede ayrı ayrı olacak şekilde uygulanarak hesaplamaları yapılmış ve çalışma alanı kapsamında alan kullanım önceliklerine uygun peyzaj deseni belirlenmiştir.

\section{a. Karar Matrisinin (A) Oluşturulması}

$$
\mathrm{A}_{\mathrm{ij}}=\left[\begin{array}{cccc}
\mathrm{a}_{11} & \mathrm{a}_{12} & \ldots & \mathrm{a}_{1 \mathrm{n}} \\
\mathrm{a}_{21} & \mathrm{a}_{22} & \ldots & \mathrm{a}_{2 \mathrm{n}} \\
\cdot & & & \cdot \\
\cdot & & & \cdot \\
\cdot & & & \cdot \\
\mathrm{a}_{\mathrm{m} 1} & \mathrm{a}_{\mathrm{m} 2} & \ldots & \mathrm{a}_{\mathrm{mn}}
\end{array}\right]
$$

\section{c. Ağırlıklı Standart Karar Matrisinin (V) Oluşturulması:}

$\mathrm{V}_{\mathrm{ij}}=\left[\begin{array}{cccc}\mathrm{w}_{1} \mathrm{r}_{11} & \mathrm{w}_{2} \mathrm{r}_{12} & \ldots & \mathrm{w}_{\mathrm{n}} \mathrm{r}_{1 \mathrm{n}} \\ \mathrm{w}_{1} \mathrm{r}_{21} & \mathrm{w}_{2} \mathrm{r}_{22} & \ldots & \mathrm{w}_{\mathrm{n}} \mathrm{r}_{2 \mathrm{n}} \\ \cdot & & & \cdot \\ \cdot & & & \cdot \\ \cdot & & & \cdot \\ \mathrm{w}_{1} \mathrm{r}_{\mathrm{m} 1} & \mathrm{w}_{2} \mathrm{r}_{\mathrm{m} 2} & \ldots & \mathrm{w}_{\mathrm{n}} \mathrm{r}_{\mathrm{mn}}\end{array}\right]$

\section{e. Ayırım Ölçülerinin Hesaplanması}

$$
S_{i}^{*}=\sqrt{\sum_{j=1}^{n}\left(v_{i j}-v_{j}^{*}\right)^{2}} S_{i}^{-}=\sqrt{\sum_{j=1}^{n}\left(v_{i j}-v_{j}^{-}\right)^{2}}
$$

\section{BULGULAR VE TARTIŞMA}

Çalışma alanı, Erzurum Yakutiye ilçesi sınırları içerisinde yer alan $197.25 \mathrm{~km}^{2}$ lik bir alanı kaplamaktadır. Çalışma alanı özelinde değerlendirme faktörleri ve alt birimleri genel olarak ele alındığında; büyük bir kısmı çayır ve tarımsal karakterde olan bir yapı sergiler. Arazi kabiliyet yetenek sınıfları açısından V. ve

\section{TOPSİS Yöntemi}

TOPSİS Yöntemi altı aşamadan oluşmakta olup yöntem aşamalarında kullanılan formüller aşağıda verilmiştir (Özkan, 2007).

\section{b. Standart Karar Matrisinin (R) Olușturulması}

$\mathrm{r}_{\mathrm{ij}}=\frac{\mathrm{a}_{\mathrm{ij}}}{\sqrt{\sum_{\mathrm{k}=1}^{\mathrm{m}} \mathrm{a}_{\mathrm{kj}}^{2}}} \quad \mathrm{R}_{\mathrm{ij}}=\left[\begin{array}{cccc}\mathrm{r}_{11} & \mathrm{r}_{12} & \ldots & \mathrm{r}_{1 \mathrm{n}} \\ \mathrm{r}_{21} & \mathrm{r}_{22} & \ldots & \mathrm{r}_{2 \mathrm{n}} \\ \cdot & & & \cdot \\ \cdot & & & \cdot \\ \cdot & & & \cdot \\ \mathrm{r}_{\mathrm{m} 1} & \mathrm{r}_{\mathrm{m} 2} & \ldots & \mathrm{r}_{\mathrm{mn}}\end{array}\right]$

d. İdeal ( $\mathrm{A}^{*}$ ) ve Negatif İdeal $\left(\mathrm{A}^{-}\right)$Çözümlerin Oluşturulması

$$
\begin{aligned}
& A^{*}=\left\{\left(\max _{i} v_{i j} \mid j \in J\right),\left(\min _{i} v_{i j} \mid j \in J^{\prime}\right\}\right. \\
& \mathrm{A}^{*}=\left\{\mathrm{v}_{1}^{*}, \mathrm{v}_{2}^{*}, \ldots, \mathrm{v}_{\mathrm{n}}^{*}\right\} \\
& A^{-}=\left\{\left(\min _{i} v_{i j} \mid j \in J\right),\left(\max _{i} v_{i j} \mid j \in J^{\prime}\right\}\right. \\
& \mathrm{A}^{-}=\left\{\mathrm{v}_{1}^{-}, \mathrm{v}_{2}^{-}, \ldots, \mathrm{v}_{\mathrm{n}}^{-}\right\}
\end{aligned}
$$

f. İdeal Çözüme Göreli Yakınlığın Hesaplanması

$$
\mathrm{C}_{\mathrm{i}}^{*}=\frac{\mathrm{S}_{\mathrm{i}}^{-}}{\mathrm{S}_{\mathrm{i}}^{-}+\mathrm{S}_{\mathrm{i}}^{*}}
$$

$\mathrm{C}_{\mathrm{i}}^{*}$ değeri $0 \leq \mathrm{C}_{\mathrm{i}}^{*} \leq 1$ aralığında değer alır ve $\mathrm{C}_{\mathrm{i}}^{*}=1$ ilgili karar noktasının ideal çözüme, $\mathrm{C}_{\mathrm{i}}^{*}=0$ ilgili karar noktasının negatif ideal çözüme mutlak yakınlığını gösterir.

VIII. sinif topraklar bulunmamakta olup, en fazla II. ve I. yetenek sinıfindaki topraklar yer almaktadır. Toprak derinliği $0-20 \mathrm{~cm}$. ve $20-50 \mathrm{~cm}$. kalınlığında olup, eğim özellikle çayır ve tarımsal alanların bulunduğu alanlarda \% 0-2, yerleşim alanlarında \% 2-6'lik bir yapı gösterir. Alanda yükseklik 1700-1850 m. arasında değişiklik göstermektedir. Büyük toprak gruplarından 
Alüvyal topraklar hakim bir yapı sergilerken, erozyon durumu "hiç yok veya çok az" olarak düzlük ovanın taban alanlarında yer almaktadır. Çalışma alanı genelinde orman varlığı bulunmamaktadır (Şekil 3). Çalışma alanında yer alan havaalanı tamamen I. sınıf araziler üzerinde yer almaktadır. Çevreyolunun ve BTC doğalgaz boru hattının ovanın ortasından geçiyor olması sulak alan, çayır alanları ve tarımsal nitelikli arazilerin üzerine baskılar oluşturmuştur. Yakutiye ilçesinin güney kısmı kentsel yerleşim alanları ile, batısı ve kuzeyi I. ve II. sinıf yetenek sinıfı arazilerin hakim olduğu çayır ve tarımsal alanlardan oluşmaktadır. Çalışma alanında değerlendirme faktörleri ve bunların alt birimlerine bağlı olarak beş farklı alan kullanım tipine göre öncelikler ÇKKV tekniği olan TOPSİS yöntemi aracıllğ 1 ile belirlenmiş̧ir. Yöntem kapsamında faktörlerin uzman görüşlerine bağlı olarak hesaplanan etki dereceleri dikkate alınarak matrisler yöntem aşamalarına göre oluşturulmuş alan kullanım tipleri için öncelik sıraları belirlenmiştir.

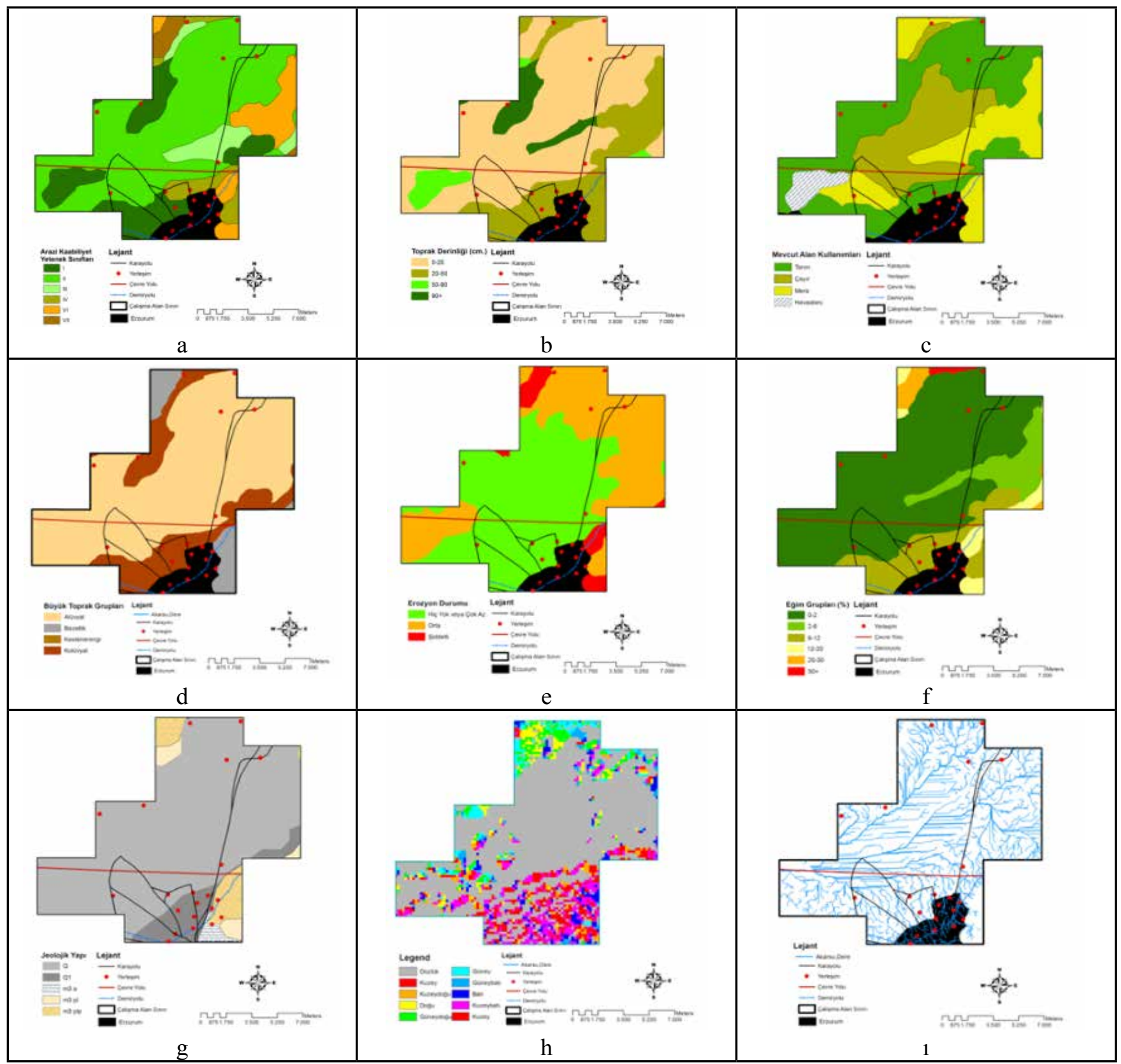

a.Arazi kabiliyet yetenek sınıfları, b. Toprak derinliği, c. Mevcut alan kullanımları, d. Büyük toprak grupları, e. Erozyon durumu, f. Egim grupları, g. Jeolojik yapı, h. Bakı grupları, 1. Hidrolojik yapı.

Şekil 3. Çalışma alanına ait sayısal haritalar 
Yöntem 789 plankarede ayrı ayrı olacak şekilde uygulanmış ve çalışma amacı olan peyzaj deseni ortaya konulmuştur. Plankarelerde öncelikli alan kullanım tiplerini ve peyzaj desenini gösteren harita Şekil $4^{`}$ de verilmiştir.

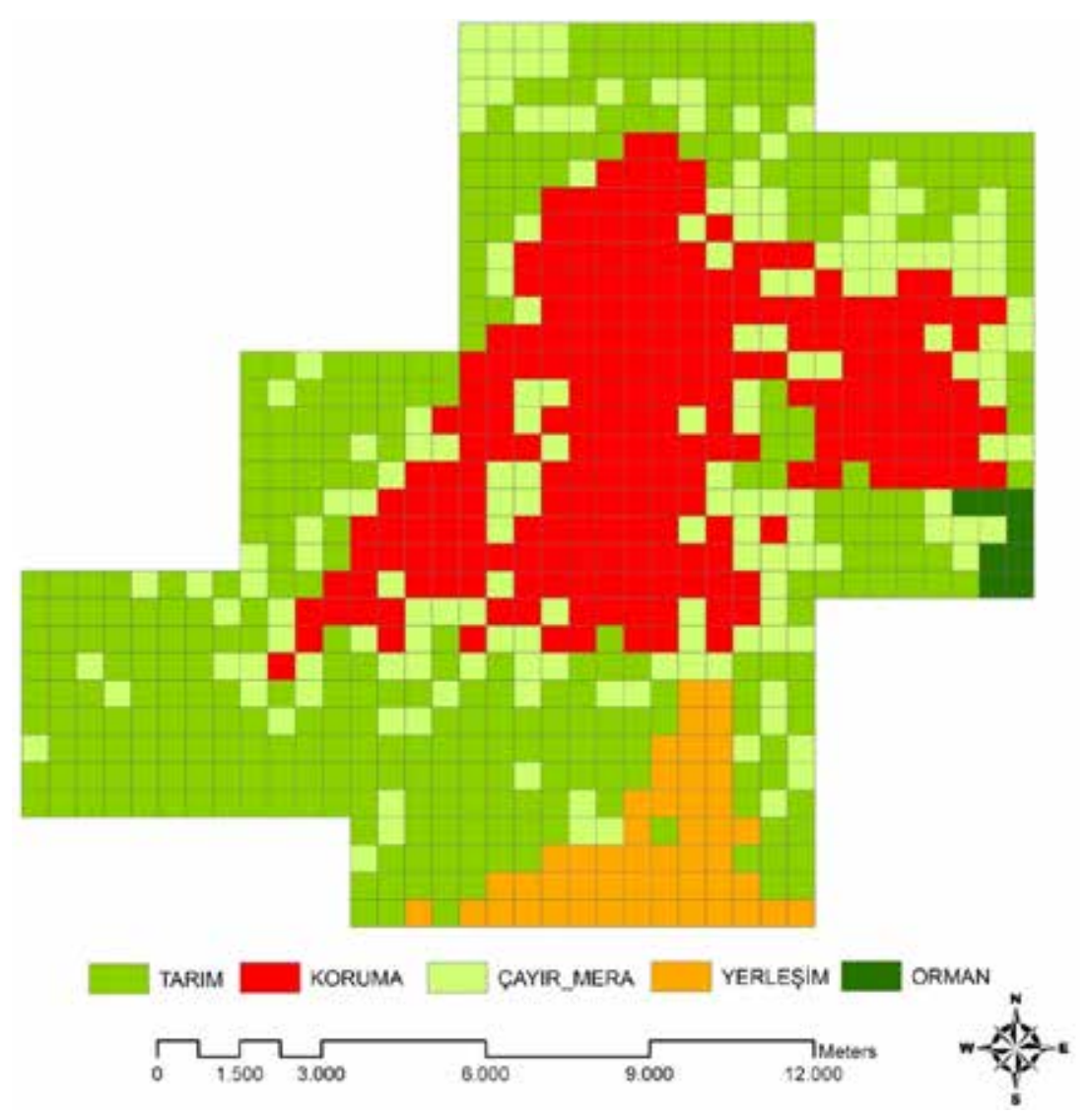

Şekil 4. Öncelikli alan kullanım tiplerine bağlı peyzaj deseni

\section{SONUÇ}

Uygulanan yöntem sonucunda 789 adet plankarenin 223'ünde koruma alanları (\% 28), 341 plankarede tarım alanları (\% 44), 168 plankarede çayır-mera alanları (\% 21), 49 plankarede yerleşim alanları (\% 6) ve orman alanları 8 plankarede (\% 1) öncelikli alan kullanımları olarak belirlenmiştir. Bu durum çalışma alanının temel olarak tarım ve koruma amaçlı kullanılması gerektiğini göstermektedir. Koruma amaçlı olarak Erzurum Bataklığ 1 diye adlandırılan sulak alan ve çevresinin ekolojik yapısının bozulmaması ve korunması gerekliliği bu çalışmada ortaya konulmuştur. Önemli kuş göç yolu üzerinde bulunan bu alanın kuşların beslenmeleri, barınmaları, dinlenmeleri ve üremeleri için ortam özelliği gösterdiğinden koruma önceliğinin planlamalarda dikkate alınması son derece önemlidir.
Mevcut alan kullanımında Erzurum Havaalanı olarak kullanılan alanın ekolojik açıdan tarımsal faaliyetler için birinci öncelikli alan olma özelliği gösterdiği tespit edilmiştir. $\mathrm{Bu}$ durum planlamadan kaynaklanan yanlış alan kullanımları için belirgin bir örnektir. Ayrıca çalışma alanında birinci önceliğin tarım ve koruma olması gereken alanlar üzerinden çevreyolunun geçmiş olması yanlış alan kullanımının katlanarak büyüdüğünün bir diğer örneğidir. Bu durum ekolojik açıdan gerek tarımsal nitelikli ve gerekse koruma amaçlı alanlar üzerinde ciddi kirlilik ve çevresel baskı oluşturarak, ekolojik süreçlere direkt etki eden bir yapı sergilemektedir.

Elde edilen peyzaj deseni genel olarak değerlendirildiğinde, alanın sırasıyla tarım, koruma ve çayır-mera ağırlıklı bir alan kullanım tipi 
göstermektedir. Yakutiye ilçesi sınırları dahilinde kentsel gelişme için ayrılabilecek alanlar hiç yok denecek kadar (\% 1) azdir.

Çalışma alanında ekolojik süreçler açısından tüm kullanım alternatifleri tükenmeden yerleşim amaçlı planlamaların yapılmaması gerekir. Aksi takdirde bu süreçler kentsel baskının var olan etkisinin daha fazla artması gibi ciddi geri dönülmez sonuçları ile karşı karşıya kalacaktır. ÇKKV tekniklerinden TOPSİS

\section{KAYNAKLAR}

Akpınar N, 1994. Açık Kömür Ocaklarında Çevresel etkilerin değerlendirilmesi ve Doğa Onarımı Çalışmalarının MilasSekköy Açık Kömür Ocağı Örneğinde İrdelenmesi, Ankara Üniversitesi Fen Bilimleri Enstitüsü Peyzaj Mimarlığı Anabilim Dalı, Doktora Tezi, Ankara

Akpınar N, 2003. Sürdürülebilir Alan Kullanım Planlamasında Alan Kullanım Tiplerine ait Önceliklerin Simos Prosedürü ve Electre-1 Yöntemi ile Belirlenmesi, Ankara Üniv. Tarım Bilimleri Dergisi, 9(2), s.234-242, Ankara

Altaban Ö, 1996. Kentsel Çevre Araştırmalarında Uluslararası Yaklaşımlar Üzerine, Çevre Planlama ve Tasarımına Bütüncül Yaklaşım Sempozyumu, 26-28 Kasım, s.143-160, Ankara

Altan T, 1991. Ekolojik Riziko Analizi ve Turizm Planlamas1, Turizm ve Çevre Konferansı, T.Ç.S.V. Yayını, Önder Matbaası, 3-5 Ekim 1990, s:75-99, Ankara

Anonim, 2013. Cihan Haber Ajans1. https://www.cihan.com.tr/tr/ sulak-alanlar-kurumasina-ragmen-kuslar-erzurum-ovasiniterketmedi-1080042.htm, (Erișim tarihi: 11 Aralık 2015)

Anonim, 2015. Doğa Derneği İnternet Sayfası. http://www. dogadernegi.org/wp-content/uploads/2015/09/09 DOGU ANADOLU.pdf, (Erişim tarihi: 12 Aralık 2015).

Anonim, 2016. Gate of Turkey. http://www.gateofturkey.com/ section/tr/318/5/doga-turizmi-kus-gozlemciligi-firathavzasi\#prettyPhoto, (Erişim tarihi: 05 Ocak 2016)

Ayhan ÇK, Hepcan Ş, 2009. Özgün Peyzaj Karakteristiklerine Sahip Mekanlara Yönelik Bir Peyzaj Planmama Yönteminin Ortaya Konulması, Tekirdağ Zir.Fak.Dergisi 6(1), s.93-105, Tekirdağ

Cheng S, Chan CW, Huang GH, 2002. Using Multiple Criteria Decision Analysis for Supporting Decisions of Solid Waste Management, Journal of Environment Science Health, Vol. 37, No. 6, s. 975-990.

Janko W, Bernroider E, 2005. Multi-Criteria Decision Making: An Application Study of ELECTRE and TOPSIS, 1-36, yöntemi ve ekolojik süreçleri dikkate alan çalışmaların önemi vurgulanarak, çalışma alanı özelinde peyzaj deseni belirlenmiștir.

Elde edilen veriler ve sonuçların yerinde yapılan değerlendirme ve gözlemleme çalışmaları neticesinde, TOPSISS yönteminin gerek peyzaj planlama gerekse diğer planlama çalışmalarında, kullanılabilirliğinin oldukça yüksek olduğu bu çalışmada tespit edilmiştir.

Karaelmas O, 2003. Çerkes Havzasının Optimal Alan Kullanımının Belirlenmesi Üzerine Bir Araştırma, Ankara Üniversitesi Fen Bilimleri Enstitüsü Peyzaj Mimarlığı Anabilim Dalı, Doktora Tezi, Ankara

Kırımhan S, 2005. Çevre Yönetimi, Nüfus, Kaynak, ve Çevre İlişkileri, Turhan Kitabevi, Çevre Yönetimi Dizisi:1, ISBN: 975- 270-859-5, Ankara

Malczewski J, 2004. GIS Based Land use Suitability Analysis: A Critical Overwiev, Progress in Planning 62, p.3-65.

OSİB, 2015. http://bolge13.ormansu.gov.tr/13bolge/AnaSayfa/ sulakalan/erzbataklik.aspx?sflang=tr, (Erişim tarihi: 10.Aralık 2015)

Özcan H, 1991. Cukurova Bölgesi Narenciye Üretim Potansiyelinin Belirlenmesi Üzerine Bir Araştırma. Yüksek Lisans Tezi, Çukurova Üniversitesi Fen Bilimleri Enstitüsü Toprak Anabilim Dal, Adana

Özkan Ö, 2007. Personel Seçiminde Karar Verme Yöntemlerinin İncelenmesi: AHP, Electre ve Topsıs Örneği, Dokuz Eylül Üniversitesi Sosyal Bilimler Enstitüsü Çalışma Ekonomisi ve Endüstri İlișkileri Anabilim Dalı İnsan Kaynakları Programı Yüksek Lisans Tezi, S.180, İzmir

Sezer H, Saatçioğlu ÖY, 2008; Düzenli Hat Deniz Tașımacılığında Nakliye Müteahhidinin Gemi Operatörü Seçimine Çok Kriterli Karar Destek Yaklaşımı, Dokuz Eylül Üniversitesi Sosyal Bilimler Enstitüsü Dergisi Cilt: 10, Sayı:4, 2008

Sahin S, 1996. Dikmen Vadisi Peyzaj Potansiyelinin Saptanmas1 ve Değerlendirilmesi Üzerine Bir Araştırma, Ankara Üniv. Fen Bilimleri Enstitüsü Peyzaj Mimarlığı Anabilim Dalı, Doktora Tezi, Ankara

Tong LI, Wang CH, Chen CC, Chen CT, 2004. Dynamic Multiple Responses by Ideal Solution Analysis, Europan Journal of Operational Research, Vol. 156, s. 433-444.

Yılmaz S, 1998. Erzurum Ovasının Optimal Alan Kullanımının Belirlenmesi, Atatürk Üniversitesi Fen Bilimleri Enstitüsü Peyzaj Mimarlığı Anabilim Dalı, Doktora Tezi, Erzurum 